\title{
Leadership and Complexity: Implications for Practice within the Advisement Leadership Bodies at Colleges and Universities
}

JEFFREY L. MCCLELLAN

Frostburg State University (United States)

\begin{abstract}
As academic advising has become more central to the work of universities and colleges, especially in relation to retention and graduation, efforts are being made to improve collaboration among different advising groups within these institutions. These efforts, at a number of campuses, include the emergence of training programs and institution level leadership bodies that oversee advising processes. Many of these efforts, however, are based on older paradigms of leadership and strategy. This article proposes a new model for guiding the work of these bodies based on more recent thinking that has emerged from the fields of leadership studies and chaos and complexity science as they relate to human behavior.
\end{abstract}

\section{A Metaphor for Leadership}

In organizations throughout the world the golden rule reigns supreme. That is to say, "he who has the gold makes the rules." Power and authority and force and control have been directly correlated with leadership for centuries. Now it appears things are changing. The rise and dominance of democratic government, the decline of respect for ecclesiastical authority, the emergence of a global, knowledge based economy, and other social, political, and economic forces are driving people towards what are considered by many to be more ethical and more participative forms of leadership (Adams, 1998; 
Bellingham, 2003; Boyatzis \& McKee, 2005; Greenleaf, 1977; Jarvis \& Tosey, 2001; Merricks, 2001; Robbins et al., 2008; Spears, 1998).

For thousands of years, leaders and those who have written about leadership have looked to the field of science for metaphors and concepts to increase and facilitate their understanding of and ability to interact with those they lead. Plato (2000) used examples from the natural world and the applied science of his day to inform his discussion of leadership in The Republic, Machiavelli (1992) used the analogies of map making and illness to describe the role of a prince and the importance of foresight, and the notions of scientific management advocated by Taylor (2001) emerged from scientists and philosophers during and after the scientific revolution and the enlightenment, many of whom came to think of organizations in terms of machinery (Bosher, 1988, p. 246-7; Jacob, 1997) Similarly, today's leaders and leadership scholars are looking to modern science for insights. In so doing, they have begun to explore and mine the territory of complexity science. While many have found this new terrain rich in metaphorical pearls of wisdom that fit nicely into their old frameworks, some authors and researchers have found a deep source of potentially revolutionary ideas that may challenge the very foundations of leadership and management science.

Whether or not such a change is likely to occur depends on the extent to which management and leadership theorists can avoid using complexity sciences as a new way of saying the same old things while, at the same time, contributing practical suggestions for addressing day to day challenges. This paper represents an attempt to draw upon the concepts of complexity science and apply them to a specific challenge related to these more global leadership issues that is plaguing institutions in higher education: how to organize and coordinate advising on an institutional level.

\section{The Problem}

Over the last decade, academic advising has received increasing attention in higher education. Light's (2001) declaration that, "good advising may be the single most underestimated characteristic of a successful college experience" (p. 81) combined with similar suggestions by other researchers and scholars (NACADA; Nutt, 2003) regarding the importance of advising in relation to student success and retention have spawned an increased focus on the importance and need for effective advising of students. Campuses have become more aware of advising models and philosophical approaches to advising, such as developmental vs. prescriptive advising (Creamer, 2000; Crookston, 1972; Gordon, 1995), advising as teaching (Lowenstein, 2005; NACADA, 2006a), advising as friendship (Rawlins \& Rawlins, 2005), and career advising (Gordon, 2006, 2007). At the same time, however, funding has been increasingly difficult to come by. Training programs for advisors are limited, and many organizations have not developed ways of coordinating advising across departments, divisions, and schools,

In response to these opportunities and issues, many campuses have begun to develop training programs and oversight/coordinating bodies for academic advising. Training programs include in-service training, provision of advisor handbooks, 
intranets, list serves, monthly information/training meetings, new advisor orientation programs, in-house conferences, and even certification programs (McClellan et al., 2008; NACADA, 2003, 2006b). Many such efforts are likely succeeding in improving the quality and consistency of information disseminated by advisors, as well as the overall effectiveness of advising. Nonetheless, without broader collaboration among advising administrators and other campus leaders these programs lack some of the strength they need to make a difference beyond the training room (ASTD Press, 2006; McClellan, 2008; Stuart-Kotze, 2006). As a result, many campuses are creating governing or collaborating bodies to oversee advising and increase collaborative, intentional efforts to improve the process. The following example of responsibilities of one such body is fairly typical of the role of these structures on campuses nationwide.

1. Routinely monitor advisement activities and make recommendations to the college administration concerning matters of process and administration.

2. Coordinate advisement activities between the academic schools, and their respective depts., the Career and Academic Counseling Center, and Career Services and Student Employment.

3. Oversee the activities of the Advisement Forum Planning Council (formally Advisement Steering Committee).

4. Establish programs for enhanced training and communication for all College advisement functions.

5. Develop appropriate benchmarks for advisement performance at all levels.

6. Implement a program for consistently monitoring and assessing performance against established benchmarks on an individual and collective basis in furtherance of an effective advisement program. (Sorenson, 2006)

At present such committees establish mission, vision, and values statements and engage in strategic planning to guide their institutions advising processes.

\section{The Traditional Response}

It is quite apparent from this description that many universities and colleges have responded to the complexity resultant from challenges surrounding advising according to a very traditional model of organizational development. This model suggests that as organizations develop and grow they increase in complexity due to the increased diversity among agents within the system, the increase in relationships between actors, and an increasingly unpredictable, challenging climate (Titcomb, 1999). Within such a context, minor changes often result in significant system level impacts and potential challenges (Waldrop, 1992). The resulting confusion and loss of control causes many leaders to view complexity as negative disorder and to strive even harder to control it. As part of the traditional, control oriented response, leaders design and implement roles to eliminate overlapping responsibilities and ensure efficiency and effectiveness through specialization and division of labor (Fayol, 2001; Smith, 2001; Taylor, 2001). They assume that such methods will bring order to chaos and stabilize an increasingly unstable system. This may, however, simply be an illusion. These tactics while providing 
structure and the appearance of order simultaneously increase complexity by fostering increased interdependence and interrelationships. Gullick (2001) describes this conundrum from the perspective of traditional management theory: "the more the work is divided, the greater is the danger of confusion, and the greater is the need for overall supervision and coordination" (p. 81).

Gullick (2001) further argues that from this separation and confusion arises the need to establish "a structure of authority, so that the work may be coordinated by orders of superiors to subordinates." (p. 81) Thus the desire to control increasingly complex systems because of one's fear of confusion gives birth to different levels of leaders and a system of bureaucracy (Gullick; Weber, 2001). Consequently, those expected to use technical skills are placed on the metaphorical "front lines" and are overseen in their labors by direct supervisors. These supervisors are overseen by higher level supervisors and ultimately, by top level leaders.

As the organization grows and leaders become limited in their capacity to adequately control the number of employees who report to them additional layers of management are added to further control the challenges generated by size. These layers, however, further distance leaders from workers and increasingly leave them out of touch with the realities of the workplace thereby cutting them off from the information they need to make good decisions (Goleman et al., 2002). As Greenleaf (1977) declares, "The pyramidal structure weakens information links, dries up channels of honest reaction and feedback, and creates limiting chief-subordinate relationships that, at the top, can seriously penalize the whole organization" (p. 76). In addition, these layers increase the number and diversity of interactions that characterize the system and create even greater potential for complex, unpredictable interaction that increase rather than diminish instability. In their attempts to control complexity and chaos, leaders merely increase it and diminish their ability to respond to it. As this occurs, they naturally return to the paradigm of control and add more leadership and mechanisms of control thereby creating a vicious cycle of counterproductive, hierarchical organizational development.

Whereas bureaucratic structure represents the context for managing complexity in this traditional model, strategic planning and management represent the processes for doing so. Strategic planning and management refer to the processes whereby an organization formulates and implements "plans to achieve [the] company's objectives" (Pearce and Robinson, 2000, p. 3). These processes typically involve developing mission, vision and values statements that serve as the compass or constitution for guiding, directing, and assessing the actions of leaders and participants within the system (Covey, 1991). Once these documents are developed, leaders evaluate the internal "tangible assets, intangible assets, and organizational capabilities," of the organization and determine which of these represent organizational strengths as opposed to weaknesses (Pearce and Robinson, p. 193). Then leaders evaluate the impact of these organizational strengths and weaknesses within the context of the opportunities and threats the company faces as a result of the interaction between the institution and its external environment. These opportunities and threats are derived from evaluating the 
remote, industry, and operational environments (Pearce \& Robinson). If this process is conducted with careful precision, leaders believe and theorists assert that organizations will develop an understanding of their current status in relation to competitors. They can then develop effective plans for managing the organization based on long- and short-term goals and strategies. Ultimately, if these plans are implemented, executed and monitored efficiently and effectively by "evaluating performance, reviewing the situation, and initiating corrective adjustments in mission, objectives, strategy, or implementation," (Thompson \& Strickland, 1993, p. 3) leaders will achieve the goals and objectives they developed as part of the planning process. In summary, organizational leaders maintain control of the organization by using a tightly controlled process to overcome complexity.

The problem with this model is it may be a myopic illusion. While leaders faithfully engage in this strategic planning and execution process firmly believing that doing so contributes to any resulting progress, in many organizations it appears that the actual day to day work of responding to complexity happens much differently. Stacey, Griffin, and Shaw (2001) explain,

What is striking is the complete lack of discussion on how [people] get things done in the day-by-day activity of organizing. If asked, they make a few remarks about personal connections, unexpected encounters, bending the rules, and lobbying for support. . . . giving the impression that they do not really know how they 'got things done'.... The experience of being 'in charge' but repeatedly finding that they are not 'in control' is a very familiar one for managers-one that they feel uneasy about and seem unable to discuss openly with each other. (p. 4)

Rather than admit, however, they do not know how they accomplished their tasks, leaders describe any success as resulting from the strategic planning and management process. The result is a process-reinforcing cycle that continues unabated in spite of its potentially limited impact on actual outcomes.

To the extent, however, that strategic planning is implemented in accordance with the traditional planning model, an entirely different, yet troublesome, reality may also emerge. Plans may become more than artifacts to be used for decision making. Instead they are reified as governing agents in the social construction process to which all other agents remain subservient (Stacey et al., 2000). Individuals then lose their capacity to make effective decisions in the micro-present (Stacey et al.) because of their dependence on the deterministic, linear, goal oriented strategic planning process (Gilstrap, 2005). Consequently, the oft stated and despised anthropomorphic dictum of the power paradigm resounds throughout the organization, "Our policy says . . .". This leads to a scenario in which autocratic power and authority are not only exercised by leaders but also upon leaders by these reified policies and procedures (Griffin, 2002).

Even in organizations where leaders practice more democratic/participative ways of influencing employees, leader-follower interactions often occur within the construct of traditional autocratic structures and planning processes. For example, Wheatley's (1999) suggestion that vision acts as a strange attractor can cause leaders to continue to set the vision in a hierarchical, imposed fashion even though the visions described by Wheatley 
emerge from group interaction (Gilstrap, 2005). Consequently, these traditional strategic planning processes and the actualities of how people respond to the complexity that surrounds them remain separate and distinct and the plans and strategies remain limited in their effectiveness.

In response to such organizational inefficiency, some more radical thinkers might call for a revolutionary upheaval designed to topple bureaucratic, control oriented leadership. In contrast, others may call for new styles of leadership that are more participative. Unfortunately, a more radical upheaval, and perhaps even a mild one, would likely change the identity of the powerful without changing the paradigms and processes they use to guide the system. This has been the case in many social revolutions. Perhaps change should begin not by changing the leaders or structures, but rather the paradigms and processes of leadership. Like their predecessors, these new paradigms and processes could likely be grounded in concepts and metaphors derived from science, specifically the science of complexity. Out of just such a conceptual genesis fundamentally different structures and processes for organizing and leading may emerge.

\section{Complexity Theory}

In order to craft an argument in support of engaging in the process of leadership based on complexity theory, it will need to address the difficulty of defining complexity science and demonstrate that this approach has something new and significant to offer to the field of leadership. As Richardson and Cilliers (2001) state, "Although a number of conferences have been held to explore the potential of complexity science within the realms of management and organization science, there still appears to be little agreement on what complexity science actually is" (p. 5). Nonetheless, these authors suggest that some agreement appears to exist regarding the central concepts of complexity theory and complex adaptive systems. Additional authors have contributed further clarity to the question of complexity science and its relevance to the social sciences and leadership (Jervis, 1997; Urry, 2005). The following discussion provides a brief description of some generally agreed upon principles that are relevant within social systems.

The Complementary Law asserts that "any two perspectives (or models) about a system will reveal truths regarding that system that are neither entirely independent nor entirely compatible" (Richardson, 2004a, p. 76). This principle is related to the discovery that light, at a quantum level, possesses the paradoxical capacity to be both a wave and a particle depending upon the means whereby it is examined (Wheatley, 1999). This discovery suggests that "For complex systems ... there exists an infinitude of equally valid, non-overlapping, potentially contradictory descriptions" (Richardson, p. 76). Thus, different perspectives complement and build upon one another in such a way that a more complete, though at times contradictory, understanding of the system emerges. This law also suggests that any single perspective holder is limited in his or her capacity to both understand the system, as well as to interact effectively within it due in part to 
the numerous variables and actors and the extensive interdependent relationships within complex systems (Titcomb, 1999; Waldrop, 1992).

In addition, the single perspective holder is further limited in his or her view of the system by previous experiences and interpretations of those experiences. His/her view depends on the capacity of the pre-frontal cortex and other neural structures to sort through abundant sensory input to identify salient information and formulate meaning patterns that engender one's perspective (Dickman \& Stanford-Blair, 2002; Goldberg, 2001; LeDoux, 1996). The resulting perspective is then largely dependent upon the previously developed mental models one carries as a result of prior experience. Different people see different salient variables and therefore comprehend or perceive complex systems in different ways as a result of the mental models they bring to any given context (Dickman \& Stanford-Blair, 2002; Senge, 1990).

Compounding this problem, particles as well as people appear to behave, at least to some extent, in accordance with the perceptions held by others about them (Arbinger Institute, 2000, 2006; Warner, 2001; Wheatley, 1999). As Maturana \& Varela (1987) wrote, "every act of knowing brings forth the world" (p. 26). Thus, through perception actors co-create both the objects they perceive and the relationships between themselves and these objects. Consequently, the multiple perspectives that exist regarding issues and concerns within a social group are of tremendous importance if the system, as a body of collective actors, is to comprehend itself and adapt in mutually beneficial ways via internal feedback, perturbation, and self-organization. The importance of this point is amplified in light of two additional principles, the systems holism principle and the darkness principle.

The systems holism principle suggests that as contributors to a system function in relationship to one another, the nature of not only the participants, but also the system is enlarged and altered. Thus, a group of interacting water molecules demonstrates the property of liquidity, which is a characteristic that none of these molecules demonstrate in isolation (Waldrop, 1992). In social systems, this concept is frequently referred to as synergy and is credited as being a positive force resulting in the ability of individuals to accomplish more in groups (Covey, 1989; Maslow et al., 1998; Swenson, 2000). However, the essence of this principle is found not in the ability to accomplish more, in some cases quite the opposite appears to be true (Lussier \& Achua, 2007), but rather in the reality that what emerges as a result of interactive behavior is often fundamentally different than what would emerge as a result of the persons operating in isolation. Consequently, social groups that work together in an interactive process produce outcomes that are both the product of individual effort and group interaction, with interaction resulting in outcomes that are unique from those that might be attained through individual effort alone. This results in a state of irreversibility that makes it impossible for the system to return to any previous state (Prigogine, 1984; Richardson \& Cilliers, 2001). Therefore, interaction within organizational systems that is characterized by the valuing of all the individual participants and a collaborative, interactive process are likely to result in increased synergy and more effective procedural and relational outcomes that could not be achieved in any other way. 
The darkness principle, or principle of incompressibility, "suggests that the best representation of a complex system is the system itself and that any representation other than the system itself will necessarily misrepresent certain aspects of the original system" (Richardson, 2004a, p. 77). The misrepresentation referred to arises because any model, whether conceptual or actual, that is developed to replicate a complex system and designed to better understand and facilitate planning and engagement within the actual system it models is based on limited perspectives and a finite capacity to reproduce the exact interactive nature and composition of the original system. To the extent that humans are modeling the system, this principle is also tied to the limited capacity of the human brain discussed previously. Any attempt to model the system either mentally or physically will, of necessity, either introduce new variables into the model or fail to reproduce variables from within the original system. Once such a model is developed and used as an artifact for engaging the system, the resulting plans are inherently flawed as a result of their having been developed to function within the model as opposed to the actual system. Furthermore, this principle is related to another law, that of requisite variety, which argues that any "good regulator of a system must contain a complete representation of that system" (Richardson, 2004b, p. 77). This is, as explained previously, impossible for human beings operating within social systems to achieve. As a result, leaders must develop plans, make decisions, and act based on models that are incapable of replicating the full complexity of the system in which their actions will occur. The resulting unintended consequences can either contribute to or impede the desired outcomes leaders seek. This reality lies at the root of one of the fundamental challenges of leadership that of acting without all the information necessary to make a perfect decision (Greenleaf, 1977).

The $80 / 20$ principle argues that "in any large complex system, eighty per cent of the output will be produced by only twenty percent of the system" (Richardson, 2004a, p. 77). While these numbers are not precise, in that the percentage of active contributors may vary across systems, the assertion that only a portion of all the actors within a system directly contribute to its output is well supported (Richardson, 2004a). However, this does not infer that the remaining actors within the system are without value.

The redundancy of resource principle assumes that redundancy contributes to stability amidst disturbances of the system (Richardson, 2004b). Thus a species that experiences low birth to maturity rates is more likely to reproduce larger quantities of offspring. Likewise, the human brain develops and later sheds excess neurons at critical developmental periods to avoid problems arising from deformations of any single neuron (Dickman \& Stanford-Blair, 2002; Howard, 2000). To the extent that redundancy exists either participants within the system or procedural activities over time will result in stability and order, especially in the face of challenges. Consequently, lean organizations may be more prone to failure when significant challenges emerge. At the same time, redundancy can result in entropy if the system becomes more closed than open, as a result of commonality, as is evidenced in social processes such as groupthink.

Finally, the principle of modularity "refers to the observation that complex systems tend to organize themselves into reasonably well defined (interactive) modules", which 
may be modular in nature or hierarchical (Richardson, 2004b, p. 77). In other words, groups of elements or agents within the system begin to form and relate in unique ways. These modules give rise to patterned behavior and strange attractors. Some of these patterns are aligned across the system with what might be called the primary work of the "legitimate system", which involves maintenance of the overall identity or attractor. Still other modules, which Burns calls "shadow modules," engage more openly with the external environment causing micro-level adaptations resulting in internal unpredictability (Burns, 2002). These different patterns and the abundance of interactions within and across systemic boundaries result in additional changes within the system that create diverse alternative forms, modules and attractors. As differentiation increases, the system moves towards greater disequilibrium. At some point, it either destabilizes or reaches a bifurcation point, wherein it comes apart as a result of the internal conflict and reorganizes around new attractors (Capra, 2002; Prigogine, 1984). This suggest that actors within complex adaptive social systems have the capacity, through their interactive nature, to collectively adapt to their environments in such a way that they overcome structural decline and, through novelty, evolve while maintaining a basic constancy of identity (Wheatley, 2007).

Central to this process is the notion of positive feedback, which "refers to supportiveness of an environment for a particular behavior or outcome" (Svyantek \& Brown, 2000). This supportiveness is not, however, focused on maintaining the status quo, but rather on exacerbating "initial stresses in the system, so rendering it unable to absorb shocks and re-establish the original equilibrium" (Urry, 2005, p. 5). In social system, positive feedback may be related to the idea of catalytic mechanisms. In his article, Collins (1999, July/August) suggests that the ability to promote and sustain change is related to the ability of an organization to implement policies and procedures that make it impossible for the system to remain in its current state. As an example, Collins refers to an organization that, in order to catalyze its goal of quality service, instituted a policy of short pay. According to this policy, customers could make deductions from their own bills based on the quality of service they received. As a result, organizational leaders were forced to adapt. As Collins explains:

In the years since it was instituted, short pay has had a profound and positive impact on Granite Rock. It serves as a warning system, providing hard-to-ignore feedback about the quality of service and products. It impels managers to relentlessly track down the root causes of problems in order to prevent repeated short payments. It signals to employees and customers alike that Granite Rock is dead serious about customer satisfaction in a way that goes far beyond slogans. Finally, it keeps Granite Rock from basking in the glory of its remarkable success. And it has had success, as has been widely reported. (p. 73)

The positive feedback created by this catalytic mechanism made it impossible for the organizational system to remain in its original state. Leaders and employees had to adapt in order to survive. The ability to support and promote novelty through just such mechanisms is central to the complex adaptive nature of systems. 
While the principles listed above seem to be generally accepted as characteristic of complex adaptive systems that are relevant within the field of leadership and management significant debate continues in relation to the overarching relevance and appropriate application of complexity theory to organizational leadership (Axelrod \& Cohen, 1999; Gilstrap, 2005; Richardson, 2004a, 2004b; Rosenhead, 1998; Stacey et al., 2000; Urry, 2005; Wheatley, 1999, 2007).

With regard to organizational leadership, one of the central tenets of complexity theory according to Axelrod and Cohen (1999) is that "Complexity deals with systems composed of many interacting agents" (p. xv). Furthermore, Axelrod and Cohen declare, "A system is complex when there are strong interactions among its elements, so that current events heavily influence the probabilities of many kinds of later events" (p. 7). These authors suggest a process of analyzing complex adaptive systems and the way in which these function to "deliberately [change] the structure of a system in order to increase some measure of performance, and to do so by exploiting an understanding that the system itself is complex" (p. 9). This strategy necessarily places the leader in a traditional role of systems analyst and presumes a capacity to maintain status within the system while engaging it as an objective, external observer. This use of complexity in relation to organizational leadership does not demand a significant alteration of either the structure or the process of traditional management science. Instead, it redirects the attention of leaders to new ways of analyzing and understanding the system as they continue to engage in traditional strategic planning and implementation. While valuable in this respect, this conceptualization of complexity nonetheless suffers from severe limitations.

One of the primary limitations of Axelrod and Cohen's (1999) definitions and strategies according to Stacey, Griffin, and Shaw (2000) is their reification of systems and the perception of the leader as an analyst that is both internal and external to the system. In addition, these authors argue that definitions like that offered by Axelrod and Cohen fail to recognize and account for the central and significant roles of unpredictability, novelty, freedom, and interaction within complex systems. Such definitions and conceptual frameworks, because of their limitations, "only provide a source domain for analogies of human action when their model or system has a life of its own" which the authors argue is a fundamental error of complexity theorists who are bound by their ties to traditional systems thinking (p. 125).

As a result of these limitations, Griffin (2002) asserts that leaders who wish to effectively engage complexity must do so not by analyzing a system but by engaging with it through a process of social interaction that respects freedom and nurtures novelty. This process involves deep, localized engagement between individuals wherein identity is constantly being constructed and reconstructed through internal and external dialectical "I"|" $\mathrm{Me}^{\prime}$ conversations that occur in the living present.

These micro-level interactions as they occur within and without organizations generatively, creatively, and unpredictably construct the future of the organization through identity negotiation, information acquisition and sharing, and relationships (Fenwick, 2008; Knowles, 2001; Wheatley, 1999, 2007). Consequently, Stacey, Griffin, 
and Shaw (2002) wrote, "what an organization becomes emerges from the relationships of its members rather than being determined by the choices of individuals" (p. 123). Within this conceptualization of complex leadership, the role of leaders is not to "step outside [the system] to operate on it or use it," but rather to engage in a process of localized "interaction, or relating, which is itself a process of intending, choosing, and acting" (Griffin, 2002, p. 187). The obvious implication of this is that leadership becomes shared across the system (Burns, 2002). Furthermore, the focus of such leadership is not only on self-organization but also on facilitating the emergence of additional leaders (Burns, 2002; Greenleaf, 1977).

Quinn (2004) argues that this kind of localized, micro-present oriented leadership is more a result of one's state of being than simply one's actions. He proposes a conceptual framework for engaging in the kind of interactional, identity creating leadership that allows leaders to metaphorically "build the bridge as they are walking on it." $\mathrm{He}$ declares, "when we are in this state, we become purpose centered, internally driven, other-focused, and externally open" (p. 21). This state of being creates openness to change, or identity creation, both internally and externally and leads to actual change. Furthermore, this process is catalytic in its effects. As Quinn states, "when we change ourselves, we change how people see us and how they respond to us. When we change ourselves, we change the world. This is the legacy of people who operate in the fundamental state of leadership" (p. 24). Warner (2001) expresses a similar notion in the following way:

When others undergo a change in heart (whether or not it happens in response to a change in us) they can influence us and help us change. For as a result of their change, they give us a different sort of person to respond to. By allowing ourselves to be touched or affected by this change in them, we are influenced to sustain our own change of heart or allow it to be deepened. Thus by letting others influence us in the first place, we may influence them to influence us even more positively than before-and this can reinforce our change of heart (p. 177).

As we engage in such deep interpersonal interaction and change, thereby coconstructing our identity, we embrace and intuitively respond to complexity and generate novelty through paradox.

While this abstract reconstruction of the role of leaders is wonderful in theory, for it to prove valid and durable, it must have some practical applications that produce result. The following section will focus on how the ideas discussed previously might be applied to leadership within governing bodies for advising on university and college campuses.

\section{Application to Advising Leadership Bodies}

How might these ideas from complexity theory be applied to conceiving advising leadership at universities and colleges? Potential answers to this question fall into three categories: those that alter the perception of governing bodies in light of complexity principles, those that alter the internal leadership processes of the bodies, and those that alter the leadership processes of the bodies in relation to the external environment. 


\section{Altered Perception of Governing Bodies}

Fundamental change requires not only changing practices, but also altering the mental models and values that underlie practices. Indeed, more often than not attempts to change practices without changing underlying mental models results in little or no change (Argyris \& Schön, 1996; Senge, 1990). Therefore, the perception of advising governing bodies, and governing bodies in general, would likely need to become more aligned with the paradigm of complexity principles. Because these bodies are, in essence, small complex adaptive systems (the committee) within larger complex adaptive systems (the university) designed to regulate a modular element of the larger system (advising), which may consist of other complex adaptive systems, the principles of complexity apply to all of these entities and can be applied to the leadership and functional processes of the group.

As an example of how these principles might alter the paradigm of leaders, consider the following. The application of complexity theory principles creates an altered vision wherein different perspectives are valued as contributing to the increased capacity to understand and engage the system (the complementary law and darkness principle), change is recognized as beginning when one first encounters the system and is facilitated through interaction within the system as opposed to imposition upon the system (the systems holism principle), redundancy is viewed as s source of potential creativity and adaptive capacity (the $80 / 20$ and redundancy of resource principles), and less control oriented self-organization processes are seen as valuable contributors to success (the principle of modularity) and facilitated using positive feedback. Such an altered paradigm would likely facilitate the emergence of altered leadership processes both within leadership bodies and between them and other constituencies.

\section{Altered Internal Leadership Processes}

The emergence of new internal leadership processes would likely involve a change in the perception and practices of those who serve in the role of leader. Instead of engaging in the role of the leader from within the paradigm of the traditional response, the perception and practice of leadership would shift towards a more fluid and responsive model consistent with principles of complexity theory. Consequently, leaders would recognize their limited capacity to understand the larger system without the involvement of the diverse, equally valid perspectives of others. They would understand the importance of broad level involvement, even allowing for some redundancy. They would recognize the importance of creating change through interactive dialogue and catalyzing the change through positive feedback mechanisms.

Consistent with these principles, leaders would behave less like the preeminent, autocrat and more as the primus-inter-pares, or first among equals. According to Heifetz (1994) leaders must first recognize that complexity demands a change in leadership from a focus on technical expertise based solution finding and autocratic decision-making to the work of adaptation. Adaptation, therefore, shifts the role of the leader from problem solver to facilitator as he or she works to manage the "conflicts in the values people 
hold, or to diminish the gap between the values people stand for and the reality they face" (p. 22). This is accomplished through focusing attention on the issues that leaders and followers face, regulating the distress levels of followers as they explore these issues, maintaining the focus on these issues as leaders and followers mutually explore and seek means for resolving problems, and ensuring that mutual responsibility for solving and addressing challenges is accepted and embraced. Leaders who engage in leadership after this fashion do so by managing conflict, accessing and disseminating information, and guiding decision-making processes.

This kind of leadership maintains influence not through retaining power, but through the distribution of it. Agendas are shared and items jointly determined. Meetings are not typically directed, but facilitated. Decisions are not ratified, accepted, or passed down directly or underhandedly. Instead, leaders and followers engage in mutual decision-making through dialogue and some form of consensus. They disseminate and examine information from multiple perspectives, rather than holding and tightly controlling it as a means of maintaining personal power. In such bodies, the position of chair may even rotate regularly rather than remain constant.

In addition to altering the process of leadership, the processes of the body would be revisited. As mentioned previously these councils often engage in traditional strategic planning processes. They seek to develop and refine the mission, vision, and values statements of advising at the institution so that the group can develop concrete, objective action plans, address issues, and assess and improve advising with these documents firmly in place. While the establishment of such documents, processes, and plans is beneficial, these tend to follow the traditional pattern of objectively interacting with the system of advising from the outside-the traditional notion of systems theory and design. This objective approach leads to many of the challenges discussed previously.

In order to alter the current direction of advising leadership committees and to implement a fundamentally different procedural means of engaging with advising, one that is informed by an understanding of principles derived from complexity science, it is perhaps best to begin by reconstructing the role of the council. The traditional role of such a council is that of governance. Functioning in this role, these governing bodies tend to be insular, closed systems that pass directives onto the rest of the organization. From a complexity perspective, this is dysfunctional at best and potentially destructive (Burns, 2002; Wheatley, 2007).

\section{Altered External Leadership Processes}

To make the body more functional, complexity principles would suggest that the system become more open. Thus the role of the group could shift to one of engagement with the multiple elements of the advising and institutional system in order to better construct the future through re-contextualizing the interactions among all participants within the institutional advising system. This conceptual and practical shift could be accomplished not by merely altering structures or establishing rules, but rather by changing the way individuals interact with one another (Wheatley, 2002). This shift to openness could begin with the committee. Committee members might change how they 
interact with each other and with the groups they are called upon to lead and represent. These interactions could involve the members actively striving to enter the purpose centered, internally driven, other-focused, and externally open state proposed by Quinn (2004).

In this process of transformation, the mission, values and vision of the group and advising in general would not be reified in a governing document, but rather reconstructed and renegotiated constantly through and within human interactions (Knowles, 2001). This procedural alteration does not preclude the writing of such documents, but rather sees them as dynamic fluctuating artifacts that influence and are influenced by interaction and engagement (Gilstrap, 2005; Wheatley, 2007). Consequently, such documents would be referred to as a guide for action that may be altered in the interactions of the living present if necessary, both as the committee seeks to make decisions and as advisors make decisions.

With regard to the process of engaging with problems, developing plans, and implementing procedures members of the committee may significantly alter their perspectives and behavior. Instead of seeing themselves as external objective judges and governors of the system, they might shift their perspective to that described by Knowles (2001) as the, "perspective of standing within the organization with people who are deeply engaged in conversations, together, clarifying who we are, and developing agreements about how we will behave and work together, as well as addressing our important issues and doing something about them" (p. 112). Thus the role of council members would be that of interactional agents who engage with the system to better assist it to self-organize in novel ways through paradox. When problems or challenges arise, such as the question of who is responsible to advise students in a given major when the advisor is on vacation, the committee members would engage with the persons involved and facilitate engagement between the parties in such a way that the problem is solved and new mutually constructed interaction processes develop for solving such problems.

This process would likely resemble the mediation process, as opposed to that of traditional judicial decision making, wherein the mediator serves as a facilitator of human interaction instead of an arbitrary decision maker. This process encourages the mediator to effectively establish rapport, build trust, listen, and collect and reconstruct information with the participants even as he or she fades into the background with regards to the actual resolution of the problem (Umbreit, 1995, p. 30). Wheatley (2007) suggested a five stage process that involves first cooling and quieting through listening and creating a shared space of identity and understanding; second, enriching understanding through fruitful opposition; third, seeking additional insight and understanding ; fourth, precise destruction of outdated paradigms, processes, policies, and procedures; and fifth, intelligent, collaborative focused action towards chance. Gerzon (2006), Heifetz (1994), and Lebaron (2003) offer similar models.

Individuals engaging in such processes reflect the essence of what Greenleaf (1998) entitled servant leadership. As he wrote, 
the difference [between traditional leaders and servant leaders] manifests itself plainly in the care taken by the servant first to make sure that other people's highest priority needs are being served. The best test, and most difficult to administer, is this: Do those served grow as persons? Do they, while being served, become healthier, wiser, freer, more autonomous, more likely themselves to become servants? (p. 19).

According to Quinn (1996), this is accomplished as leaders engage in the following paradoxical behaviors: responsible freedom, tough love, reflective action, authentic engagement, appreciative inquiry, grounded vision, adaptive confidence, and detached interdependence (p. 89). These behaviors are manifestations of apparently contradictory value sets ${ }^{1}$ that contribute to effective leadership as leaders hold and engage in these paradoxical values amidst challenging circumstances by recognizing their underlying complementary nature (Kelso \& Engstrøm, 2006). For example, it is often the case that amidst such challenges, leaders feel a strong need to respond to the demands of powerful constituencies who represent only one end of the paradoxical values continuum. This is particularly true in politically charged contexts.

Heifetz (1994) provides an excellent example of both the demands of such situations as well as the means of addressing them in his discussion of President Johnson's response to violence in Selma, Alabama during the Civil Rights Movement. In the wake of the violence, numerous efforts were made to encourage the president to act immediately to restore peace and protect the activists. These requests were based upon and appealed to people's desire for peace, security, and justice. They did not, however, recognize that without the conflict, instability, and recognition of injustice that accompanied Johnson's delayed response, lasting fundamental change in society was unlikely. As Heifetz, explains, "Adaptive work requires a change in values, beliefs, or behavior. The exposure and orchestration of conflict--internal contradictions--within individuals and constituencies provide the leverage for mobilizing people to learn new ways." (p. 22).

In order to accomplish this work, leaders can begin by recognizing the contradictory values at play and reflecting on how such values might be held in paradoxical tension by engaging in behaviors that reflect both sets of values simultaneously (Kelso \& Engstrøm, 2006). In so doing, they resist the tendency to make choices based on limited, culturally appropriate values. For example, the western managerial tradition is biased towards tough, independent action. In President Johnson's case, acting in accordance with these values would have required immediate, strong action to either support the state in its efforts to stop the marchers or to support and protect the marchers. Either approach would have failed to recognize the need for change and the reality that such change required a reexamination and balancing of paradoxical values. In this case, these paradoxical partners included: caring, interdependent, reflection. Johnson new that he

\footnotetext{
${ }^{1}$ Note that this discussion of values in relation to the application of complexity theory to leadership practice introduces the issue of imposing prescriptive ethical norms into the discussion of descriptive complexity processes. Fenwick (2008) appropriately cautions against blurring the lines between morality and complexity, but likewise recognizes the need for such a connection.
} 
needed broad support to bring about change and that this would require that he demonstrate not only the capacity for strong independent action, but that he also demonstrate a concern for the challenges of all the parties involves. Likewise he had to recognize the interdependent nature of those involved and promote the reflection that would be necessary to bring others to a state of readiness to change. Consequently, Johnson moved behind the scenes to draft strong civil rights legislation and to pressure the governor of Alabama to request aid, while at the same time working with civil rights leaders to keep the pressure on while avoiding actions that would likely trigger more violence. As a result, Johnson was able to hold the relevant values simultaneously, in apparent paradox, and act in accordance with them, thereby effectively managing the crisis.

Leaders such as Johnson do not, however, bring about change by simply developing the capacity to hold values in paradox and by acting accordingly. Instead, they do so by also developing the capacity to facilitate this process among their followers. Presidents have advisors who serve to provide them with multiple perspectives on issues. Based on the principles of complexity and systems theory, leaders will likely benefit from encouraging the participation of individuals with diverse backgrounds, values, and perspectives that best reflect those within the larger system in which they operate. When issues arise, these multiple perspectives allow the leader to see the complex system in a more complete way than he or she would based solely on his or her own limited perspective. Effective feedback mechanisms from within the larger system that represent similarly diverse perspectives and values further strengthen this capacity. The group is then more able to make decisions that balance the different competing values inherent within the system and to hold these in sustained paradox. Through this group process, individual leaders are likewise strengthened in their personal capacity to do the same.

In order to facilitate such interaction, the traditional means of selecting the membership of advising leadership bodies may also need to be revisited. Often, a decision about who sits on these bodies is determined from within the traditional power paradigm. People in positions of leadership are chosen based on their legitimate and political power within the institution. They are the leaders who stand outside the system and pass judgment. If, however, the relational processes of the committee are to change to more of a mediating role that holds values in paradoxical tension, then the members of the committee should probably change to facilitate this. Members would then represent multiple layers of the hierarchy and diverse values orientations and perspectives. Furthermore, some fluidity of membership would also likely occur based on the immediate needs and issues under consideration by the body. It may even be that the committee comes to function more like a town hall than a committee (Gilstrap, 2005).

Encouraging the broader participation, feedback, and interaction necessary to facilitate effective decision making, these bodies would likely utilize previously unused technology, as well as making use of familiar technology in ways these have not previously been used. Open discussion boards, wikis, shared web documents, webcasting and instant messaging may prove useful in bringing people together and tapping in to the relational structure of the organization in new and creative ways. 
Obviously these suggestions possess a vagary that may limit their credibility among traditional leaders. If this is the case, then they may be rejected for being too novel as Gardner suggests (1999). While this may perhaps be unavoidable, it may also be impossible to define and prescribe the behaviors of such leaders without eliminating the very complexity required to engage in such leadership. Indeed, it is unlikely that any clearly prescribed set of practices could be developed for transplantation to other settings as effective practices, by the very nature of complex adaptive systems, must emerge from within the system. On the other hand, practices may emerge from within one context that could serve as artifacts for consideration and adaptation within another context. As Wheatley (2007) suggests, these serve to inspire further innovation rather than as solutions to simply apply. This, in turn, may lead to entirely new even more complexity oriented processes and ways of structuring organizations. Over time, the results may indeed be revolutionary.

\section{Conclusion}

In conclusion, the notion of complexity may have a lot to contribute to the discussion of effective leadership in a global change oriented society that is truly deepening in complexity. In this paper the question of how this contribution might occur has been explored in relation to institution-wide advising leadership bodies at universities and colleges. While the concepts and ideas developed here have specific implications for leadership within such bodies, the potential suggestions they give birth to may proffer new ways of thinking about and engaging in both the process of leadership and ultimately the structure within which it occurs on a broader scale. If this proves true, a revolutionary reconstruction of society could emerge over time: a society wherein the golden rule, as previously alluded to, no longer exists. The paradox is that this revolution may simply embrace the reality of how things already are; and yet, in so doing, freedom and novelty may be unleashed in ways that they have not been previously. While this is, perhaps, idealistic and utopian thinking, maybe, just maybe, something great can come of such a small shift in mind and process.

\section{References}

Adams, M. (1998). The stream of labor slows to a trickle. HRMagazine Retrieved December 7, 2000, from http://www.shrm.org/hrmagazine/articles /1098cov.htm

Arbinger Institute. (2000). Leadership and self-deception: Getting out of the box. San Francisco: Berrett-Koehler. Arbinger Institute. (2006). The anatomy of peace: Resolving the heart of conflict. San Francisco: Berrett-Koehler. Argyris, C., \& Schön, D. A. (1996). Organizational learning ii. Reading, Mass.: Addison-Wesley Pub. Co. ASTD Press. (2006). Improving human performance (1st ed.). Alexandria, VA: ASTD Press.

Axelrod, R. M., \& Cohen, M. D. (1999). Harnessing complexity: Organizational implications of a scientific frontier. New York: Free Press.

Bellingham, R. (2003). Ethical leadership: Rebuilding trust in corporations (2nd ed.). Amherst, Mass.: HRD Press. Bosher, J. F. (1988). The french revolution (1st ed.). New York: W.W. Norton.

Boyatzis, R. E., \& McKee, A. (2005). Resonant leadership: Renewing yourself and connecting with others through mindfulness, hope, and compassion. Boston: Harvard Business School Press. 
Burns, J. S. (2002). Chaos theory and leadership studies: Exploring uncharted seas. Leadership and organizational studies, 9(2), 42-56.

Capra, F. (2002). Complexity and life. Emergence, 4(1/2), 15-33.

Collins, J. (1999, July/August). Turning goals into results: The power of catalytic mechanisms. Harvard Business Review), 71-82.

Covey, S. R. (1989). The seven habits of highly effective people. New York: Simon and Schuster.

Covey, S. R. (1991). Principle-centered leadership. New York: Summit Books.

Creamer, D. G. (2000). Use of theory in academic advising. In V. N. Gordon, Habley, W. R., and Associates (Ed.), Academic advising: A comprehensive handbook (1 ed., pp. 18-33). San Francisco: Jossey-Bass.

Crookston, B. B. (1972). A developmental view of academic advising as teaching. Journal of College Student Personnel, 13, 12-17.

Dickman, M. H., \& Stanford-Blair, N. (2002). Connecting leadership to the brain. Thousand Oaks, CA: Corwin Press.

Fayol, H. (2001). General principles of management. In J. M. Shafritz \& J. S. Ott (Eds.), Classics of organization theory (pp. 48-60). Belmont, CA: Wadsworth.

Fenwick, T. (2008). Responsibility, complexity science and education: Dilemmas and uncertain responses. Studies in Philosophical Education, 28, 101-118.

Gardner, H. (1999). Intelligence reframed: Multiple intelligences for the 21rst century. New York: Basic Books.

Gerzon, M. (2006). Leading through conflict: How successful leaders transform differences into opportunities. Boston: Harvard Business School.

Gilstrap, D. L. (2005). Strange attractors and human interaction: Leading complex organizations through the use of metaphors. Complicity: An international journal of complexity and education, 2(1), 55-69.

Goldberg, E. (2001). The executive brain: Frontal lobes and the civilized mind. New York: Oxford University Press.

Goleman, D., Boyatzis, R., \& McKee, A. (2002). Primal leadership. Boston, MA: Harvard Business School Press.

Gordon, V. N. (1995). Developmental advising. In D. S. Crockett (Ed.), Advising skills, techniques, and resources: A compilation of materials related to the organization and delivery of advising services (pp. 147161). Iowa City, IA: The American College Testing Program.

Gordon, V. N. (2006). Career advising: An academic advisor's guide (1st ed.). San Francisco, CA: Jossey-Bass.

Gordon, V. N. (2007). The undecided college student: An academic and career advising challenge (3rd ed.). Springfield, Ill.: Charles C Thomas.

Greenleaf, R. K. (1977). Servant leadership: A journey into the nature of legitimate power and greatness (25th Anniversary ed.). New York/Mahwah, NJ: Paulist Press.

Greenleaf, R. K. (1998). Servant leadership. In L. Spears (Ed.), Insights on leadership: Service, stewardship, and servant leadership. (pp. 15-20). New York: John Wiley and Sons.

Griffin, D. (2002). The emergence of leadership: Linking self-organization and ethics. London: Routledge.

Gullick, L. (2001). Notes on the theory of organization. In J. M. Shafritz \& J. S. Ott (Eds.), Classics of organization theory (pp. 79-87). Belmont, CA: Wadsworth.

Heifetz, R. A. (1994). Leadership without easy answers. Cambridge, MA: Belknap Press of Harvard University Press.

Howard, P. J. (2000). The owner's manual for the brain: Everyday applications from mind-brain research. Austin, TX: Bard Press.

Jacob, M. C. (1997). Scientific culture and the making of the industrial west. New York: Oxford University Press.

Jarvis, P., \& Tosey, P. (2001). Corporations and professions. In P. Jarvis (Ed.), The age of learning: Education and the knowledge society (pp. 147-156). London, UK: Kogan Page.

Jervis, R. (1997). System effects: Complexity in political and social life. Princeton, N.J.: Princeton University Press.

Kelso, J. A. S., \& Engstrøm, D. A. (2006). The complementary nature. Cambridge, MA: MIT Press.

Knowles, R. N. (2001). Self-organizing leadership: A way of seeing what is happening in organizations and pathway to coherence. Emergence, 3(4), 112-127.

LeBaron, M. (2003). Bridging cultural conflicts: A new approach for a changing world (1st ed.). San Francisco: Jossey-Bass.

LeDoux, J. E. (1996). The emotional brain: The mysterious underpinnings. New York: Touchstone Book. 
Light, R. J. (2001). Making the most of college: Students speak their minds. Cambridge, MA: Harvard University Press.

Lowenstein, M. (2005). If advising is teaching, what do advisors teach? NACADA Journal, 25(2), 65-73.

Lussier, R., \& Achua, C. (2007). Leadership: Theory, application, and skill development (3 ed.).

Machiavelli, N. (1992). The prince (N. H. Thompson, Trans. Unabridged. ed.). New York: Dover Publications.

Maslow, A. H., Stephens, D. C., \& Heil, G. (1998). Maslow on management. New York: John Wiley.

Maturana, H. R., \& Varela, F. J. (1987). The tree of knowledge: The biological roots of human understanding (1st ed.). Boston: New Science Library.

McClellan, J. L. (2008). Bridging the gap between training and performance through advisor training and development. The Mentor: An Academic Advising Journal, Online at www.psu.edu/dus/mentor.

McClellan, J. L., Moser, C., \& J., W. (2008, February 11). Advisor certification at utah valley state college. NACADA Clearinghouse of Academic Advising Resources Web site, from http://www.nacada.ksu.edu/Clearinghouse/AdvisingIssues/Adv-Cert.htm

Merricks, L. (2001). The emerging idea. In P. Jarvis (Ed.), The age of learning: Education and the knowledge society (pp. 3-15). London, UK: Kogan Page.

NACADA. Advising and retention quotes. NACADA Clearinghouse of Academic Advising Resources Retrieved June 20, 2008, from http://www.nacada.ksu.edu/Clearinghouse/Advisingissues/retentionquotes.htm

NACADA. (2006a). National academic advising association concept of academic advising. Retrieved March 6, 2007, from http://www.nacada.ksu.edu/Clearinghouse/AdvisingIssues/ConceptAdvising.htm

NACADA (Ed.). (2003). Advisor training: Exemplary practices in the development of advisor skills. Monograph series 9. Manhattan, KS: National Academic Advising Association.

NACADA (Ed.). (2006b). The new advisor guidebook: Mastering the art of academic advising through the first year and beyond. Monograph series, no 16. Manhattan, KS: National Academic Advising Association.

Nutt, C. L. (2003). Academic advising and student retention and persistence. NACADA Clearinghouse of Academic Advising Resources Retrieved June 20, 2008, from http://www.nacada.ksu.edu/Clearinghouse/AdvisingIssues/retention.htm <retention.htm>

Pearce II, J., \& Robinson, J., Richard. (2000). Strategic management: Formulation, implementation, and control (7 ed.). Burr Ridge, IL: Irwin.

Plato. (2000). The republic (B. Jowett, Trans.). Mineola, NY: Dover.

Prigogine, I. (1984). Order out of chaos: Man's new dialogue with nature. New York: Bantom Books.

Quinn, R. E. (1996). Deep change: Discovering the leader within. San Francisco: Jossey-Bass.

Quinn, R. E. (2004). Building the bridge as you walk on it: A guide for leading change. San Francisco: Jossey-Bass.

Rawlins, W. K., \& Rawlins, S. P. (2005). Academic advising as friendship. NACADA Journal, 25(2), 10-19.

Richardson, K. A. (2004a). Systems theory and complexity: Part 1. E:CO, 6(3), 75-79.

Richardson, K. A. (2004b). Systems theory and complexity: Part 2. E:CO, 6(4), 77-82.

Richardson, K. A., \& Cilliers, P. (2001). What is complexity science? A view from different directions. Emergence, 3(1): 5-23.

Robbins, S. P., DeCenzo, D. A., \& Moon, H. (2008). Fundamentals of management: Essential concepts and applications (6 ed.). Upper Saddle River, NJ: Pearson/Prentice Hall.

Rosenhead, J. (1998). Complexity theory and management practice. Retrieved May 9, 2009, from http://www.human-nature.com/science-as-culture/rosenhead.html

Senge, P. M. (1990). The fifth discipline: The art and practice of the learning organization. New York: Doubleday/Currency.

Smith, A. (2001). Of the division of labor. In J. M. Shafritz \& J. S. Ott (Eds.), Classics of organization theory (pp. 37-41). Belmont, CA: Wadsworth.

Sorenson, S. (2006). Uv advisement model. Unpublished manuscript.

Spears, L. C. (1998). Tracing the growing impact of servant-leadership. In L. Spears (Ed.), Insights on leadership: Service, spirit, and servant-leadership (pp. 1-14). New York: John Wiley and Sons.

Stacey, R. D., Griffin, D., \& Shaw, P. (2000). Complexity and management: Fad or radical challenge to systems thinking? London: Routledge.

Stuart-Kotze, R. (2006). Performance: The secrets of successful behaviour. London: Financial Times Prentice Hall. 
Svyantek, D. J., \& Brown, L. 1. (2000). A complex systems approach to organizations. Current Directions in Psychological Science, 9(2), 69-74.

Swenson, C. (2000). Tools for teams: Building effective teams in the workplace. Boston: Pearson Custom.

Taylor, F. W. (2001). The principles of scientific management. In J. M. Shafritz \& J. S. Ott (Eds.), Classics of organization theory (pp. 61-72). Belmont, CA: Wadsworth.

Thompson, A. A., \& Strickland, A. J. (1993). Strategic management: Concepts and cases (7 ed.). Boston, MA: McGraw-Hill/Irwin.

Titcomb, T. J. (1999). Chaos and complexity theory. In C. S. Russo (Ed.), Organizational development: An infoline collection for training and development professionals. Alexandria, VA: American Society of Training and Development.

Umbreit, M. S. (1995). Mediating interpersonal conflicts: A pathway to peace. West Concord, MN: CPI.

Urry, J. (2005). The complexity turn. Theory, culture, \& society, 22(1-14).

Waldrop, M. M. (1992). Complexity: The emerging science at the edge of order and chaos. New York: Simon and Schuster.

Warner, C. T. (2001). Bonds that makes us free: Healing our relationships, coming to ourselves. Salt Lake City, UT: Shadow Mountain.

Weber, M. (2001). Bureaucracy. In J. M. Shafritz \& J. S. Ott (Eds.), Classics of organization theory (pp. 73-78). Belmont, CA: Wadsworth.

Wheatley, M. J. (1999). Leadership and the new science: Discovering order in a chaotic world (2nd ed.). San Francisco: Berrett-Koehler.

Wheatley, M. J. (2002). Turning to one another: Simple conversations to restore hope to the future (1st ed.). San Francisco: Berrett-Koehler Publishers.

Wheatley, M. J. (2007). Finding our way: Leadership for an uncertain time. San Francisco: Berrett-Koehler Publishers.

\section{About the author}

Jeffrey McClellan is an Assistant Professor of Management at and the former Director of Advisor Training and Development at Utah Valley State College in Orem, UT. He has worked as an advisor, counselor, faculty member, and administrator at four different institutions over the past 10 years. Jeff holds a Ph.D. in Leadership Studies from Gonzaga University and serves as the outgoing Chair of the Commission on the Theory and Philosophy of Advising. His research interests include: Servantleadership development, organization and individual growth development and change, academic and career advising, and conflict management. Jeffrey lives with his wife and five children in Cumberland, MD. He can be contacted at: jlmcclellan@frostburg.edu

(C) Copyright 2010. The author, JEFFREY L. MCCLELLAN, assigns to the University of Alberta and other educational and non-profit institutions a non-exclusive license to use this document for personal use and in courses of instruction provided that the article is used in full and this copyright statement is reproduced. The author also grants a non-exclusive license to the University of Alberta to publish this document in full on the World Wide Web, and for the document to be published on mirrors on the World Wide Web. Any other usage is prohibited without the express permission of the authors. 